\title{
High School Students' Written Argumentation Qualities with Problem-Based Computer-Aided Material (PBCAM) Designed about Human Endocrine System
}

\author{
Gülşah Sezen Vekli' ${ }^{1, *}$, Atilla Çimer ${ }^{2}$ \\ ${ }^{1}$ Department of Mathematics and Science Education, Faculty of Education, Bozok University, Turkey \\ ${ }^{2}$ Department of Mathematics and Science Education, Faculty of Education, Karadeniz Technical University, Turkey
}

Copyright $\bigcirc 2017$ by authors, all rights reserved. Authors agree that this article remains permanently open access under the terms of the Creative Commons Attribution License 4.0 International License

\begin{abstract}
This study investigated development of students' scientific argumentation levels in the applications made with Problem-Based Computer-Aided Material (PBCAM) designed about Human Endocrine System. The case study method was used: The study group was formed of 43 students in the 11th grade of the science high school in Rize. Human Endocrine System Argumentation Texts (HESAT) was used to determine the students' scientific argumentation levels made before and after the applications with PBCAM. Besides, "PBCAM Student Records" were investigated to determine students' scientific argumentation levels on three different problems in relation to Human Endocrine System during the applications with PBCAM. Within the scope of the research problem, semi-structured interviews were made with 10 students among the participants after the application as well. Students' scientific argumentation levels were assessed with a rubric prepared by one of researchers within the framework of the scientific discussion model Sampson and Clark [1]. The qualitative results indicated that: applications made with PBCAM improved students' skills for presenting claims, proofs, reasoning and conceptual quality of the claims in scientific argumentation. Also, it was seen that "the Observation" section presented as a source of information in the PBCAM was effective on improving students' conceptual understanding. From this point of view, similar applications can be used also in teaching other biology subjects similar to endocrine system topic, which does not provide opportunities to conduct experiments and observations and which is hard to understand.
\end{abstract}

Keywords Scientific Argumentation, Problem-Based Computer-Aided Material, High School Students

\section{Introduction}

Studies researching the issues where students have difficulties in biology lessons and the reasons behind such difficulties reveal that "Human Endocrine System" subject is among the first subjects which students have difficulties comprehending $[2,3,4,5]$. Considering that one of the most basic goals of the biology program is to make students acquire basic knowledge regarding their bodies and environment, the necessity and the importance of learning the subject of "Human Endocrine System" regulating all the metabolic events in the human body becomes clear. The reasons why students had difficulties learning this subject were specified in the relevant literature as the subject containing intense and invisible, that is, abstract concepts, not being able to associate the learning with the daily life during the learning process and students not having experiences regarding the subject based on experiments or observations.

When the attainments to be obtained from "Human Endocrine System" subject in the biology teaching program are investigated, it is seen that students' skills such as problem solving, researching, organizing information and using information and communication technology tools were mentioned [6]. However, no model guiding material containing active learning methods to give the skills mentioned in the program was encountered. Similarly, the fact that no model application regarding how information and communication technology tools would be used within the scope of this program was included to the new program is also striking.

One of the active learning methods that can be used in the lessons for giving students the skills envisaged in the program and revealing the close relationship between the subject of "human endocrine system" and the daily life is Problem Based Learning (PBL). Positive results obtained from the studies, in which PBL was applied and assessed, also support this idea $[7,8,9,10,11,12,13,14,15,16,17$, $18,19,20,21,22,23,24,25,26]$.

In the literature, it is possible to encounter studies revealing the limitations in the application process of 
problem based learning. The disadvantages of the method can be summarized as follows in the studies reaching results in line with this idea: 1 . More time is required for the applications of problem based learning $[18,27] 2$. Problems used in problem based learning being not interesting or motivating for the students [28]. 3. Teachers having problems in terms of directing the process of problem based learning $[27,28,29,30]$. 4. Studies suggesting students acquired less or incomplete information in problem based learning $[9,18,31,32]$ and finally 5 . Having problems in terms of assessment in problem based learning [33].

With regard to how these limitations encountered in problem based learning can be reduced by means of multimedia developed in a computerized environment, researchers argue the following: Computers provide facilities such as ensuring richer concepts in PBL applications, individualizing applications, feedbacks and reflections, making it possible to access the desired information independently of time and space and making more realistic assessments $[9,18,32,33]$.

This situation pushed researchers to conduct studies combining problem based learning and computer environment in recent years $[34,35]$. When the learning level and the studies conducted with problem based learning environments developed in computer environment are investigated, it is seen that problem based learning applications integrated with computer environments reduced the number of some limitations, which might be encountered in the traditional problem based learning, and contributed to the development of problem solving skills of the students [14, 35, 36, 37, 38, 39, 40, 41].

Problem solving skill requires the processes of developing an appropriate solution for the problem and supporting this solution with data and proof. These processes are ensured by means of scientific argumentation (Jonassen, 2010). Scientific discussion is closely related to problem solving skills and includes problem solving argumentation because it contains the dimensions of inquiry or supporting and defending or convincing [42].

It helps students develop their problem-based learning environments encouraging them to have scientific argumentation and reveals the qualities of the scientific argumentation students have in these environments. For example, in their study, in which, they investigated structures of the argumentation made by 87 high school students during the problem solving process, by means of computer-aided problem-based software, Sandavol and Millwood [43] recorded and subsequently analyzed all the actions taken by the students during the problem solving process regarding two problems about natural selection. As a result of the study, it was revealed that the students paid attention to use proof in their argumentation texts to support their claims but they did not use enough proof supporting these claims. In addition to that, it was determined that the students failed to explain how the resources they used in the argumentation were related to certain claims they made.
Köroğlu [44], on the other hand, investigated the effect of a problem based simulation environment $\mathrm{s} / \mathrm{he}$ developed for heredity topic on the students' academic success and level of using scientific argumentation elements. Ninety-five eight grade students participated in the study, which was conducted using the experimental method. The control group and three experimental groups, four groups equal in terms of gender and the results of the reading comprehension test (IOWA) were determined. The experimental group 1 learned in a simulation environment supported by guiding questions based on teaching by argumentation and argumentation elements while the experimental group 2 learned in a simulation environment supported by guiding questions based on argumentation element, the experimental group 3 learned in a simulation environment without support and the control group learned by means of the traditional method. Academic success test, scientific argumentation integrative scoring guide and scientific argumentation analytic scoring guide were used as data collection tools during the study conducted in a period of 7 weeks. Academic success test and argumentation texts were applied on all the groups before and after the application. As a result of the study, it was determined that there were no significant differences between the mean scores of the experimental group 1 and the experimental group 2 in terms of academic success, argumentation analytic post-test scores and argumentation integrative post-test scores and, the mean scores of these two groups differed significantly from the mean scores of the experimental group 3 and the control group. This study is important because it shows that scientific argumentation elements can be indirectly taught to students by means of answers given to the questions asked in a computer-aided learning environment.

Like Köroğlu, Belland, Glazevski and Richardson [45] also included guiding questions in the problem-based computer-aided software they developed about human genome project and they investigated the effect of these guiding questions on the skills of primary school students for establishing proof-based arguments. Different types of guiding questions were included to 'the Connection Log' part of the software. As a result of the study, to which 86 seventh grade students participated, it was shown that guiding questions had a significant effect on the argument establishment skills of the student groups. The guiding questions helped students considerably to establish communication and organize information. It is suggested in the study that 'the Connection Log' part may help primary school students in terms of defining the problem better, researching about the relevant information and establishing more consistent arguments during the process of establishing arguments.

A similar study was conducted by Sampson and Gleim [46] to improve students' comprehension of biology concepts. For this purpose the researchers developed a laboratory software based on scientific argumentation-oriented study. This software developed for the molecular foundations of 
heredity allows students to structure their scientific argumentation by encouraging them to explain the questions in the study. Researchers specify that argumentation-oriented teaching software based on research will contribute to ensure that students assume more responsibility about their own learning.

In this respect, it is possible to say that the number of studies regarding the subject is scarce, if any, especially about the domestic biology education. In addition to that, no similar study regarding high school biology lessons in our country was encountered among the resources that were accessed. From this point of view, a problem-based learning material encouraging students to have scientific argumentation is developed and it is thought that the results to be obtained using this material and the current study investigating the development of the scientific argumentation establishing skills of the students will fill the gap in this area.

A problem-based learning materials about "Human Endocrine System" integrated with computer environment was developed in this study and it was aimed to investigate the development of students' scientific argumentation levels in the applications made with this material.

\section{Method}

The purpose of this study was to investigate the scientific argumentation levels of the students during the applications made Problem-Based Computer-Aided Material (PBCAM) developed about Human Endocrine System. For this reason, this study was conducted with the case study method.

Considering the easy access by the researcher, time and accommodation conditions, the study was conducted in Rize province. A preliminary study was made to determine teachers' and school administrators' attitudes regarding this study and the physical conditions that the schools have to conduct this study at a minimum level. As a result of this study, among three schools with the necessary physical conditions the science high school in Rize province where positive attitude was displayed regarding the study was chosen to conduct the study.

The study group was formed of $43(22+21)$ students from two different classes (class B and class C) in the 11th grade of the same school. It is obtained essential permissions from Ministry of National Education via petition. Demographic characteristics of these students are summarized in Table 1.

Table 1. Demographic characteristics of study group $(n=43)$

\begin{tabular}{|c|c|c|c|c|c|c|c|c|}
\hline \multirow{2}{*}{ Class } & \multirow{2}{*}{ Number of student } & \multicolumn{4}{|c|}{ Gender } & \multicolumn{5}{|c|}{ Biology score } \\
\cline { 3 - 9 } & & $\mathbf{F}$ & $\mathbf{M}$ & $\mathbf{1}$ & $\mathbf{2}$ & $\mathbf{3}$ & $\mathbf{4}$ & $\mathbf{5}$ \\
\hline B & 21 & 6 & 15 & - & 2 & 5 & 8 & 7 \\
\hline C & 22 & 6 & 16 & - & 3 & 6 & 7 & 5 \\
\hline Total & 43 & 12 & 31 & - & 5 & 11 & 15 & 12 \\
\hline
\end{tabular}

Within the scope of the research problem, semi-structured interviews were made with 10 students among the participants. Creswell [47] underlines that the group of the interviewed individuals should have a homogeneous structure to be able to reflect the general situation. According to this opinion, their conceptual understanding was taken as basis and a total number of 10 students ( 3 students from the lower level, 4 students from the middle level and 3 from the higher level) were selected according to the scores they got from the Human Endocrine System Conceptual Understanding Pre-test (HESCUPT). In addition to that, the voluntariness of the students, who participated in the interview, was also taken into consideration at this stage.

\subsection{Human Endocrine System Argumentation Texts (HESAT)}

A survey form named Human Endocrine System Argumentation Texts (HESAT) was developed to determine the qualities of the scientific argument made by the students before and after the applications conducted together with PBCAM. HESAT is formed of three similar problem situations appropriate for the content of the problem situations in the application process. One of the problem situations is the arranged version of the problem scenario developed by Güneş [48] within the scope of this postgraduate thesis study. Others were developed by the researcher. Opinions and suggestions were taken from a specialist physician working in the Endocrinology and Metabolism Diseases Department of Trabzon Numune Hospital during the development stage of the problem scenarios in HESAT.

The survey form is formed of problem scenarios and the scientific argumentation based guiding questions regarding these scenarios.

\subsection{Problem-Based Computer-Aided Material Student Records}

"PBCAM Student Records" were investigated to determine the qualities of the scientific argumentation made by the students on three different problems they encountered in relation to Human Endocrine System during the applications made with PBCAM. The students inexperienced about problem-based learning needed much guidance during this process $[28,29,30,49]$. PBCAM was developed with the support of guiding questions to direct the problem solving processes of the students and structure their scientific argumentation during this process. These questions were developed by based on the guiding questions in the thesis study about scientific argumentation conducted by Köroğlu [44]. Answers given by the students for each problem situation during the application process are recorded by the system. The system makes it possible for the researcher to see the answers given by the students during the application process whenever $\mathrm{s} / \mathrm{he}$ desires to do so.

\subsection{Interview}

Semi-structured interviews were made with the students in 
the study group after the application in order to determine the students' opinions about PBCAM and applications made together with this material. This interview study was conducted according to "the Interview Form" approach of Patton [50]. There is a directive section in the first part of the interview form specifying the purpose of the interviews. The second part includes questions to determine students' opinions regarding PBCAM and the activities during the application process.

\subsection{Problem-Based Computer-Aided Material (PBCAM) Design}

The model named 3C3R presented by Hung [51] was taken as basis while developing the problem-based computer-aided material [52]. The model supports students in acquiring various mental skills such as reasoning and problem solving while learning the concepts related to the lessons during the solving process of the problem presented as a concept [51, 53]. It also allows the designers inexperienced about this model of problem-based learning to develop efficient problems by following a systematic method. The students need to follow the steps specified below during the solving process of a problem scenario in PBCAM (see Figure 1):

1. Investigating problem situation (monitoring/reading)

2. Investigating the task part

3. Making explanations regarding the guiding questions based on argumentation elements

4. Investigating research menu (observation, laboratory test results, physical findings, relevant links)

5. Collection of data (proof) and writing them in "Take Notes" section
6. Making explanations regarding the guiding questions based on argumentation elements

7. Repeating the steps above when necessary

The links for "Physical Symptoms, laboratory Test Results, Observation and the Relevant Links" containing proof elements are under the "Research" menu in the material. Students can investigate the connections in this menu, note their reasoning and deductions and reveal the cause and effect relationships about the problem.

Physical Symptoms: This is the section including the proof elements about the problem. This section includes guiding questions encouraging students to reason and the "Take Notes" link making them take notes the deductions.

Laboratory Test Results: This is the section including the proof elements about the problem. This section includes guiding questions encouraging students to reasoning and the "Take Notes" link making them note their deductions.

Observation: This is the section containing the proof elements about the problem. This environment is formed of simulations and animations. With this feature, it can be considered as the visual source of information allowing students to observe the duties of endocrine glands and hormones during the problem solving process. This section includes guiding questions encouraging students to reasoning and the "Take Notes" link making them note their deductions.

The Relevant Links: This is the section containing the proof elements about the problem. This section includes pdf files containing detailed information about Human Endocrine System subjects. Similar to the other sections, this section also includes guiding questions encouraging students to reason and the "Take Notes" link making them note their deductions.

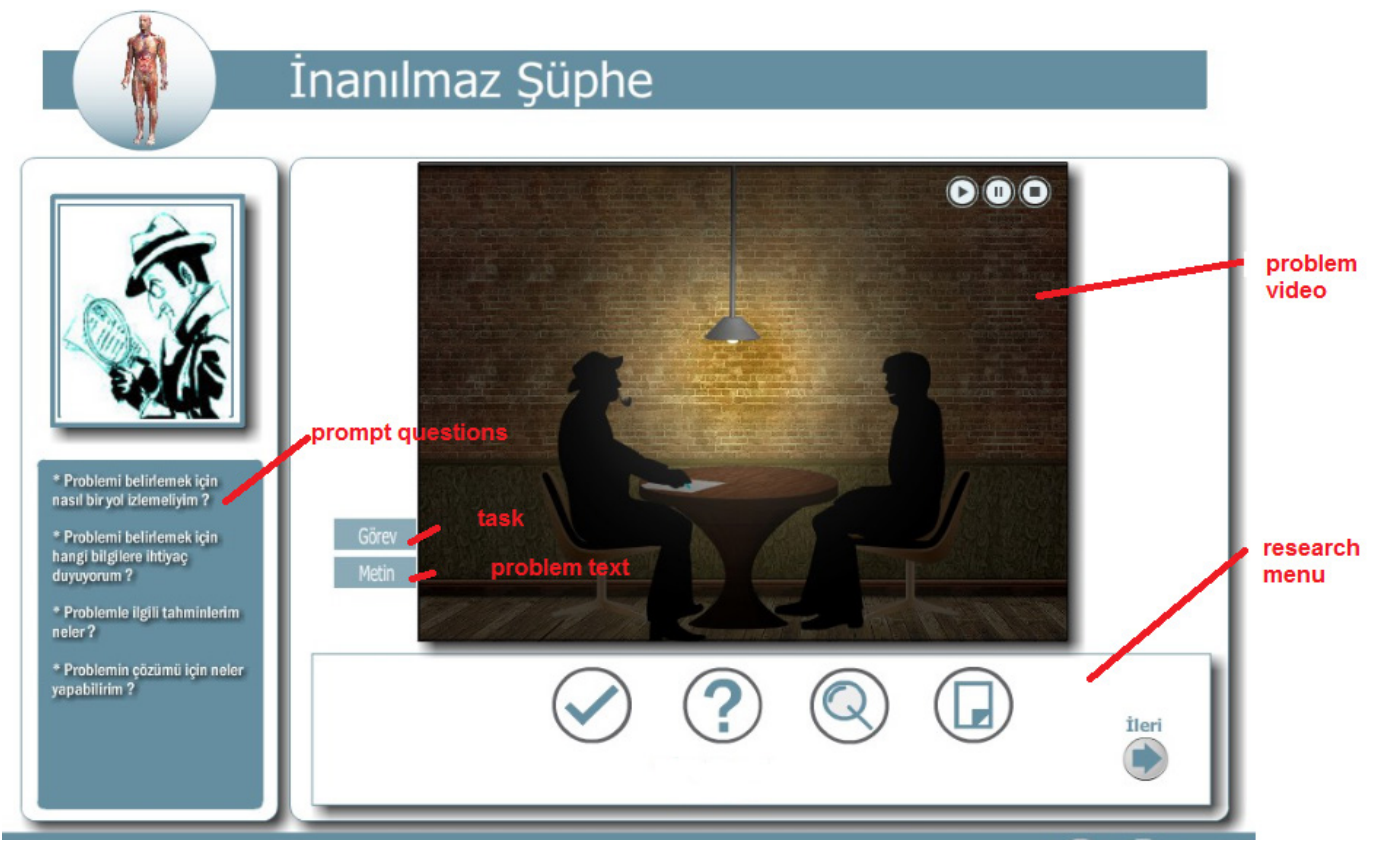

Figure 1. A screenshot of Problem-Based Computer-Aided Material 
Administrator Panel: Answers given by the students for argumentation-based guiding questions during the process of problem solving and the notes they took can be seen by the administrator in this section.

The opinions of experts comprising academicians in the area of biology teaching, biology teachers and academicians in the area of education technologies were obtained to assess the usability of PBCAM. As a result of the assessment, it was determined that PBCAM was adequate in terms of content, design and format compatibility [54].

\subsection{Implementation Process}

The application was made in a period of one and a half months by one of the researchers. An informative lecture of one hour was allocated to provide general information regarding the use, the process and the assessment of PBCAM. Information guides prepared for the use of PBCAM containing these subjects were distributed to the students at the end of the lessons. Theoretical information regarding secretory glands and endocrine glands subjects, which should be known before starting to learn Human Endocrine System, was given to the students as preliminary information.

Groups were determined for the group works to be done in the problem solving process at this stage. Heterogeneous groups were made according to the suggestions of the class teacher. The groups were formed of 4 or 5 students. Firstly, the students were asked about a problem situation in video format which is called as "Is Shrek real?" By means of the projector in the classroom the students watched it twice and those asking for the textual form of the problem situation could read it on the screens of the computers they need. The students filled individual and group problem scenario analysis forms, respectively, as a part of the lesson.

The researcher asked guiding questions and tried to activate the preliminary knowledge of the students about the problem at this stage. In the next lesson, students investigated the activities in PBCAM and tried to answer the guiding questions prepared based on argumentation elements during this process. In another lesson, students made research as a group for the research report they needed to prepare regarding the solution of the problem and started to write research reports. The students made presentations in groups in the final lesson allocated for the problem scenario. A research report prepared by the students as a group is presented below. The total amount of time allocated to each group for presentations is 10 minutes. Self-Assessment Form was distributed to the students to fill it outside the lesson time and it was collected in the next lesson.

The basic stages followed above were followed in a similar way for the other problem scenarios for another two weeks. HESCAPT and argumentation text was applied to the students one week after the application process. In addition to that, interviews were made with 10 students predetermined according to preliminary HESCAPT results.

\subsection{Data Analysis}

In this study, the quality of the scientific argumentation that students had during the applications made with PBCAM were assessed with a rubric prepared within the framework of the scientific argumentation model Sampson and Clark [1] presented by taking basis Toulmin's "Scientific Argumentation Elements" model. Scientific argumentation model developed by Sampson and Clark [1] is comprised of explanation (Similar to Toulmin's claim element), proof (similar to Toulmin's data element), reasoning (similar to the combination of Toulmin's guarantee and support elements) and the conceptual quality of the claim.

a Explanation (claim) element contains explanations regarding the answers of the students for the research questions (argumentation-based guiding questions). At this stage, an explanation made by the students requires providing a solution for a problem, expressing a descriptive relation or presenting a causal mechanism.

b Proof element defines the whole data supporting the compliance and validity of the explanations made by the students. Proof can contain various kinds of information ranging from numeric data to observation data.

c Reasoning element of the model defines the process of supporting why the claim is valid by associating it with reasonable proof.

d Sampson and Clark [1] underline that students' comprehension about a subject is also important for the scientific argumentation that students will have regarding a subject. For this reason, researchers handled the conceptual quality of the claims presented by the students as a separate element in this model.

An analytical assessment guide (rubric) was developed according to the model mentioned above in order to determine the quality of the scientific argumentation made by the students during the applications made with PBCAM. In this assessment guide developed by the researchers, elements of claim, proof, reasoning and the conceptual quality of the claim were divided into levels considering the criteria suggested according to the scientific argumentation model of Sampson and Clark [1]. These criteria can be summarized as relevancy, importance, clarity/ understandability, validity and reliability of the scientific argumentation element and its quantitative sufficiency. According to this, five levels (0, 2, 46 and 8) were formed for every scientific argumentation element in the assessment guide (claim, proof, reasoning and the conceptual quality of their claims).

With the aim of ensuring the reliability of the Scientific Argumentation Elements Usage Level Assessment Guide according to the suggestions of LeCompte and Goetz [55] the strategy of including another researcher to the process while analyzing the obtained data and confirming the results that were obtained. Within this context, double-coding procedure method specified by Miles and Huberman [56] was used. A PhD candidate, who completed his M.A. thesis 
in Scientific Argumentation Teaching in the area of Science Teaching, joined the researcher in the analysis process of the data.

During this process, the other researcher was informed about using PBCAM and Argumentation Elements Usage Level Assessment Guide before the analysis in order to improve the reliability within the framework of Luft's [57] suggestion. The other researcher could not be included to the analysis of all the data because there were too many participants, hence, too much data. Instead of this, the data set, which will represent approximately $20 \%$ of all the data, could be analyzed with the other researcher. Preliminary argumentation texts, application texts and the final argumentation texts of 8 students randomly chosen among the participants were analyzed independently by both researchers. At this stage, all the answers given by the students for each problem were assigned to a level using the assessment guide containing the usage levels of argumentation elements and the relevant definitions.

Reliability between the researchers was determined as 0.82 for the claim element while it was determined as 0.76 for the proof element, as 0.73 for the reasoning element and as 0.91 for the conceptual quality of claim element. Miles and Huberman [56] stated that a percentage at and above $70 \%$ indicated reliable coding. The fact that the agreement percentage calculated for all the scientific argumentation elements in this study are above $70 \%$ indicates that the Scientific Argumentation Elements Usage Level Assessment Guide is consistent and reliable.

Content analysis approach was adopted in the analysis of the interview data considering it as more appropriate for the nature of the research problem. Within this context, similar interview data was compiled within the framework of certain concepts and themes and organized in a way that is understandable by the reader. This structure was revealed by the researcher by subjecting the collected data to an inductive analysis since there was no conceptual structure to guide the analysis of the collected data.

Another researcher was included to the process to ensure the reliability of the data from the interviews that were made and the results were confirmed. Within this context, a researcher, who had his doctoral education in the area of chemistry teaching and who is experienced in content analysis, joined the original researcher in analyzing part of the interview data. Interview data of two randomly chosen students (a dataset that corresponds to $20 \%$ of the whole interview data) was independently subjected to a content analysis by the two researchers. Themes and sub-themes obtained by both researchers were compared as a result of the content analysis and an agreement percentage of $86 \%$ was ensured in this study. This situation indicates that the coding made during the content analysis was reliable. Besides, in the findings section, direct quotes were made from the interview data in order to present the reader how the themes and sub-themes were obtained more objectively.

\section{Findings and Discussion}

This section contains findings about the developed PBCAM and the development that occurred in the scientific argumentation levels of the students during the applications made with this material. Within this context, findings regarding the elements of claim, proof and reasoning used by the students in the scientific argumentation and the conceptual quality levels of the claims they made are presented in the subheadings.

\subsection{Findings Regarding the Students' Usage Level of the Claim Element}

The claim element in this study is defined as students' expressing a definitive relationship, providing a solution for a problem or presenting a causal mechanism in scientific argumentation they made individually.

Approximately $97 \%$ of the students' claims before the application are at level 2 and 4 while the levels of the claims by the students increased to 4 and $6(84 \%)$. Application process developed students' skills for making claims (see figure 2). A similar case is observed in the text of the final argumentation made after the application. It is even seen that the percentage of the claims made at level 8 during this stage $(12.4 \%)$ increased approximately three times compared with to the ones during the application process. All these values show that students' skills for making claims were improved by PBCAM and the applications made together with this material.

An important point that drew attention during the application process was that the students wrote the proof element instead of the claim element. For example, in a problem situation named "the Unbelievable Suspicion", S47 developed the following claim for the argumentation-element based guiding question "What can be Halit Bey's cause of death?": "Parathormona being secreted less than the normal value range". However, this is a proof element which the students can obtain from the Laboratory Test Results in PBCAM while making researches during problem solving process and use to support their valid claims. This example and similar examples were encountered in the scientific argumentation made by the students before and during the application process in particular. Similar results were obtained from the studies by Kuhn and Reiser [58], Choi, Notebaert, Diaz and Hand [59]. As Aldağ [60] and Bell and Linn [61] specified, the reasons for this situation may be the students' lack of preliminary information, superficiality of the information they have or their tendency to ignore alternative explanations. 


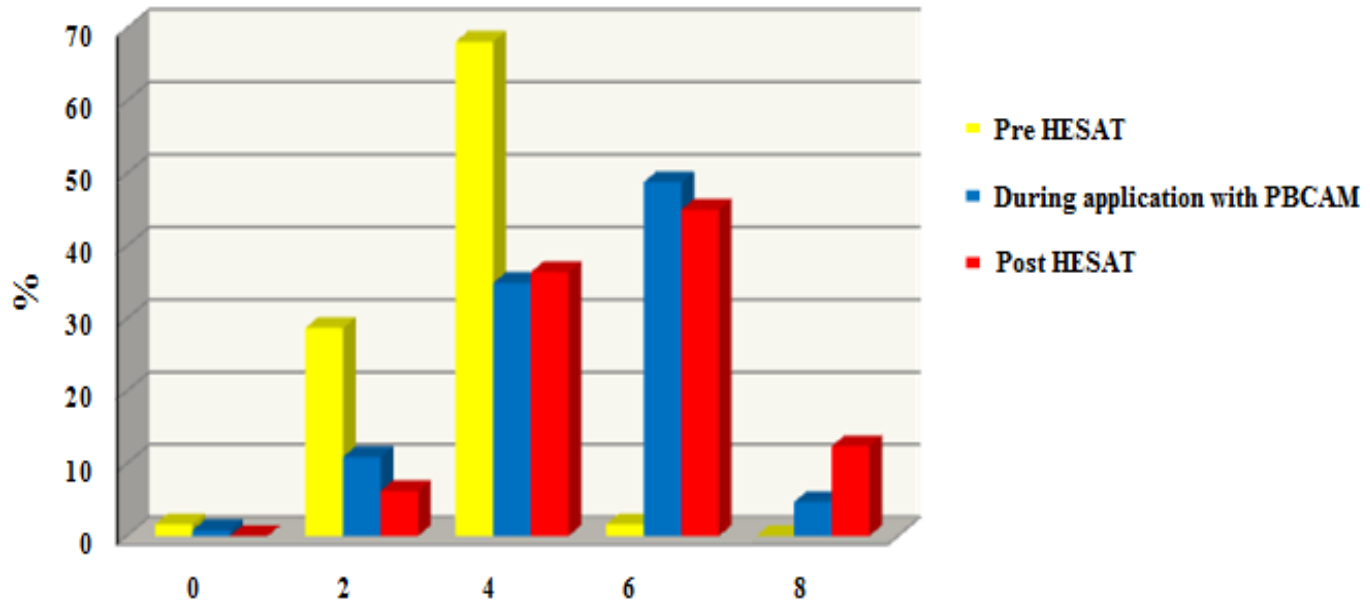

Figure 2. The students' usage level of the claim element

In such environments, where most of the learning responsibility is undertaken by students, students try to create solutions for the given problems while structuring their information at the same time. The students may prefer to present claims with superficial information instead of inquiring about and researching cause and effect relation in depth during the problem solving process. As a matter of fact, similar results were obtained also from the current study. Ekinci's [62] study conducted with 3428 students shows that students mostly employ superficial learning approach while handling a learning subject. Ramsden [63] specifies that these approaches of students are closely related to their previous experiences. Similarly, Cuthbert [64] underlines that past experiences of the students especially regarding their learning about the subject and their understanding of the subject affects the approaches students prefer in a certain learning environment. At this point, it is seen that students preferred the superficial learning approach in the lessons carried out with a focus on transferring the knowledge. Considering the opinion above, the reason why students tend to make superficial explanations during the application made with PBCAM may be because their past learning experiences were generally based on obtaining information from outside. The following statement of a student obtained during an interview supports this opinion.

S7: “...The teachers have been speaking and we have been receiving, we have been receiving for 11 years... our minds are getting used to this. As I said, we are dulling our researching skills. We dulled it for 11 years. It is not so easy to revive it in a short period of moment. For example, you came and we slowly started after a period of 2-3 weeks but I think this is not our full performance yet. We could be better than this. For example, I think we can be much more successful if we start to use this system in the middle school. We will already be doing the things before you tell us to do so and tell us what we will research for and where we will research for it, I think we will be more successful in researches etc. that way."

\subsection{Findings Regarding the Students' Usage Level of the Proof Element}

Proof element defines the whole data supporting the compliance and validity of the explanations made by the students in this study. It is seen that the students presented proof to support the ideas they suggested in their scientific argumentation with the applications made with PBCAM. When proofs presented by the students in their scientific argumentation before, during and after the application are investigated, it is seen that approximately $90 \%$ of the proofs the students presented before the application were at level 2 and 4 while these levels regarding the proofs provided by the students increased to $4(52.7 \%)$ and $6(32.6 \%)$. Application process developed students' skills for presenting proof. On the other hand, a slight decrease was observed in the rates of the proofs presented at the levels of 4 and 6 in the final argumentation text after the application while an increase was observed in the rates of proof presented at level 8 compared with to the ones in preliminary argumentation text and application process. All these values show that students' skills for presenting proof were improved by PBCAM and the applications made together with this material (see figure $3)$. 


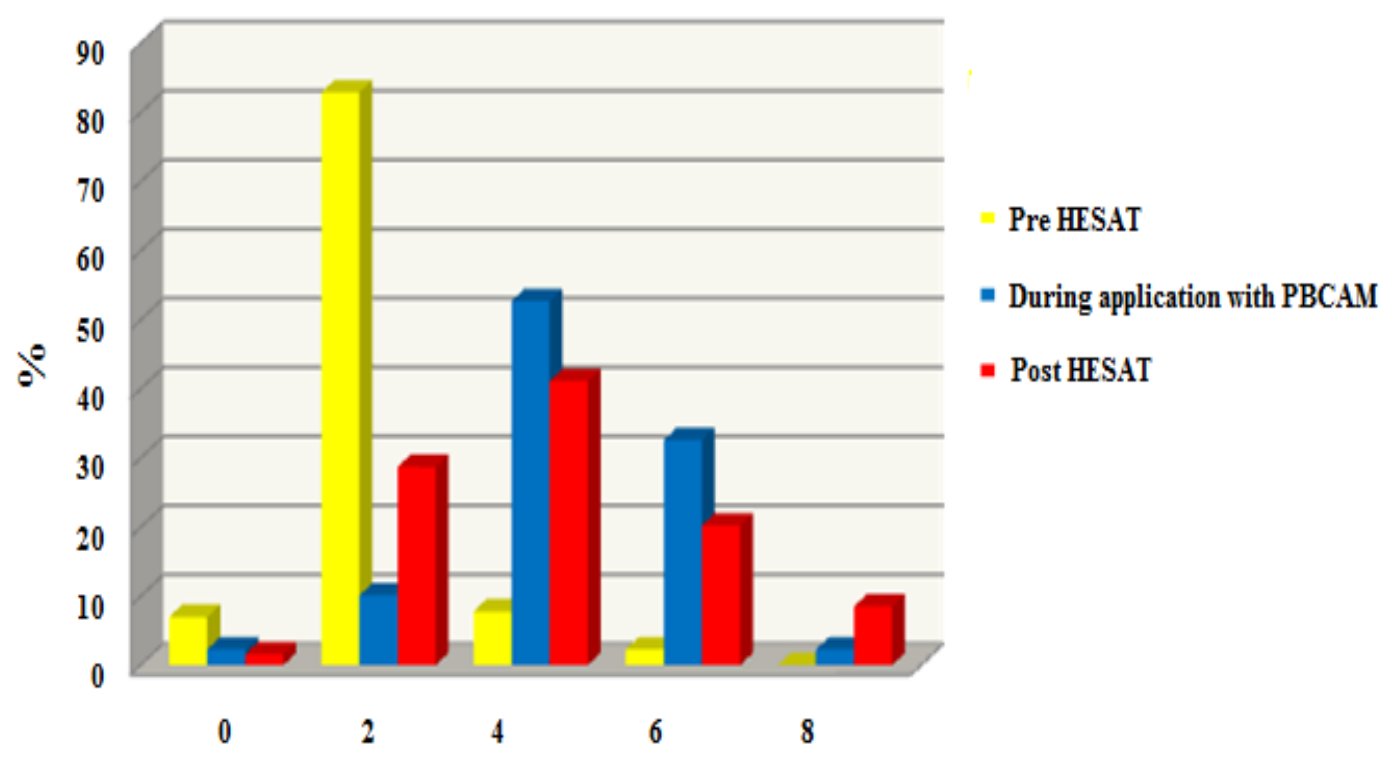

Figure 3. The students' usage level of the proof element

On the other hand, when the whole process is taken into consideration in general, it was determined that the students had difficulties in presenting the proofs they needed to use to support their claims. This finding is in parallel with the results of the studies by Kuhn and Reiser [58], Sandavol and Reiser [65], Keys [66], Yerrick [67], Sandavol and Millwood [43] and Dawson and Wenvile [68]. Results of another study made in evolutionary biology support the finding above [69]. It was suggested in the study that the students did not present enough proof to support their claims regarding the natural selection concept or they could present a very small number of proof in this regard. Sandoval and Reiser [65] and Yerrick [67] explains this situation with the claim that the students, who are used to learn by regular telling and teaching of a lesson, have difficulties to develop general strategies or strategies specific to the areas while using scientific argumentation elements. Similarly, Aldağ [60] defines the students' lack of skills for using scientific argumentation elements as a natural result of not including methods supporting thinking and discussing skills in their education.

These reasons suggested by Sandoval and Reiser, Yerrick and Aldağ can be the reasons why the students have difficulties in presenting a sufficient amount of strong proof in their scientific argumentation. In addition to that, the students' tendency to make superficial explanations because they are bored of making explanations can be considered as another reason for this situation. The students' opinions received during the interviews together with the observations made during the application process support this assumption. During the application process, students generally tended to give short answers to the questions. Short answers given are not recorded to the system because of the character limit of the answer section of PBCAM questions. It was observed that the students encountered the warning "Your answer could not be recorded in the system since it was short" while answering the questions during the application process, especially in the first weeks. Also, the following statement of a student revealed during an interview can be considered as another indicator of the students' tendency to give short answers.

S9: "I was a little bit bored. There were mostly verbal questions, the questions to which we would have to make long explanations to answer. This is why I was a little bit bored"

On the other hand, an issue that drew attention during the application was that the students often used the information in the Observation section and the information regarding the Laboratory Test Results in PDBD as proofs to support their claims while they rarely used the information in the Physical Symptoms and the Relevant Links section. The studies by Fischer, Troendle and Mandl, [70] and Krange and Ludvigsen [40] revealed that the students were not interested in electronic textual information and they did not use these parts a lot. As Y1ldırım [71] specified, this situation might be associated with the fact that the students are more interested in learning stimulus addressing to more than one sensory organ.

Similarly, information regarding Laboratory Test Results section was noted in the Take Notes section in the Research Menu while information regarding other sections was rarely noted. This situation may result from the students' tendency to make superficial explanations for the questions in PBCAM. As it was specified above, students avoided making verbal explanations during the application process. A similar situation might be discussed for the research menu sections containing mostly textual information. It was observed that the students did not take many notes regarding these sections requiring them to write long verbal statements. However, it was seen that they used the information regarding these sections as proof in the answers for the questions asked in the system. Another reason why students did not use "Take Notes" section while researching during 
the problem solving process may be that they were inexperienced about researching. The statements made by some students during the interview also support this opinion.

Another thing that drew attention during the application was that the students had a tendency to often avoid the proofs not supporting their claims when they encountered such proofs. For example, values of some hormones in the Laboratory Test Results in PBCAM were intentionally given by the researcher as low or high values very close to the normal values (reference values). On the other hand, when the answers given by the students for the argumentation-based questions were taken into consideration, it was seen that the students did not use this information they considered to be not related to their claims as proof or they did not make any explanations regarding why these were invalid proofs for them. Chinn and Brewer [72] also determined in their study that the students gave similar reactions such as avoiding the proofs when they encountered proofs that did not support their claims and completely excluding such proofs from the claim. As specified by Aldağ [60] and Bell and Linn [61], the reason for this may be the students' tendency to ignore alternative explanations other than the claims they made.

It was determined that the students did not use all of the proof elements in their problem situations to support their claims in final argumentation text just as in the application process. The reason for this may be the inexperience of the students in making scientific argumentation or the students' not being able to fully comprehend the concepts involving the problem [69]. This study was conducted in over a short period of four weeks. The researcher making the application informed the students about scientific argumentation before the application and provided guidance during the process. However, the students could not be made to do model applications in these subjects because the time allocated for this study was limited. Limitations such as the shortness of application period and the students' not making any similar applications regarding the subject may have been ineffective in terms of eliminating the students' inexperience in making scientific argumentation. This assumption is confirmed by the experimental study by Köroğlu [44] The researcher determined that although there was no difference in terms of using other scientific argumentation elements before the application, there was a significant difference about the level of using the proof element between the students, on whom scientific argumentation teaching and applications were made, and the students on whom such applications were not made.

\subsection{Findings Regarding the Students' Usage Level of the Reasoning Element}

Reasoning element in this study defines the process of supporting why the claim is valid by associating it with reasonable proof (Sampson and Clark, 2008). When the level of reasoning students used in their scientific argumentation before, during and after the application are investigated, it is seen that approximately $90 \%$ of the reasoning was at level 2 and 4 before the application while these levels by the students of reasoning were increased to $4(49.6 \%)$ and 6 (18.6\%) (68.2\%). Application process developed students' skills for reasoning (see figure 3). On the other hand, a slight decrease was observed in the rates of the reasoning at the levels of 4 and 6 regarding the final argumentation text after the application while an increase was observed in the rates of reasoning at level 8 compared with to the ones in preliminary argumentation text and application process. All these values show that students' skills for reasoning were improved by PBCAM and the applications made together with this material.

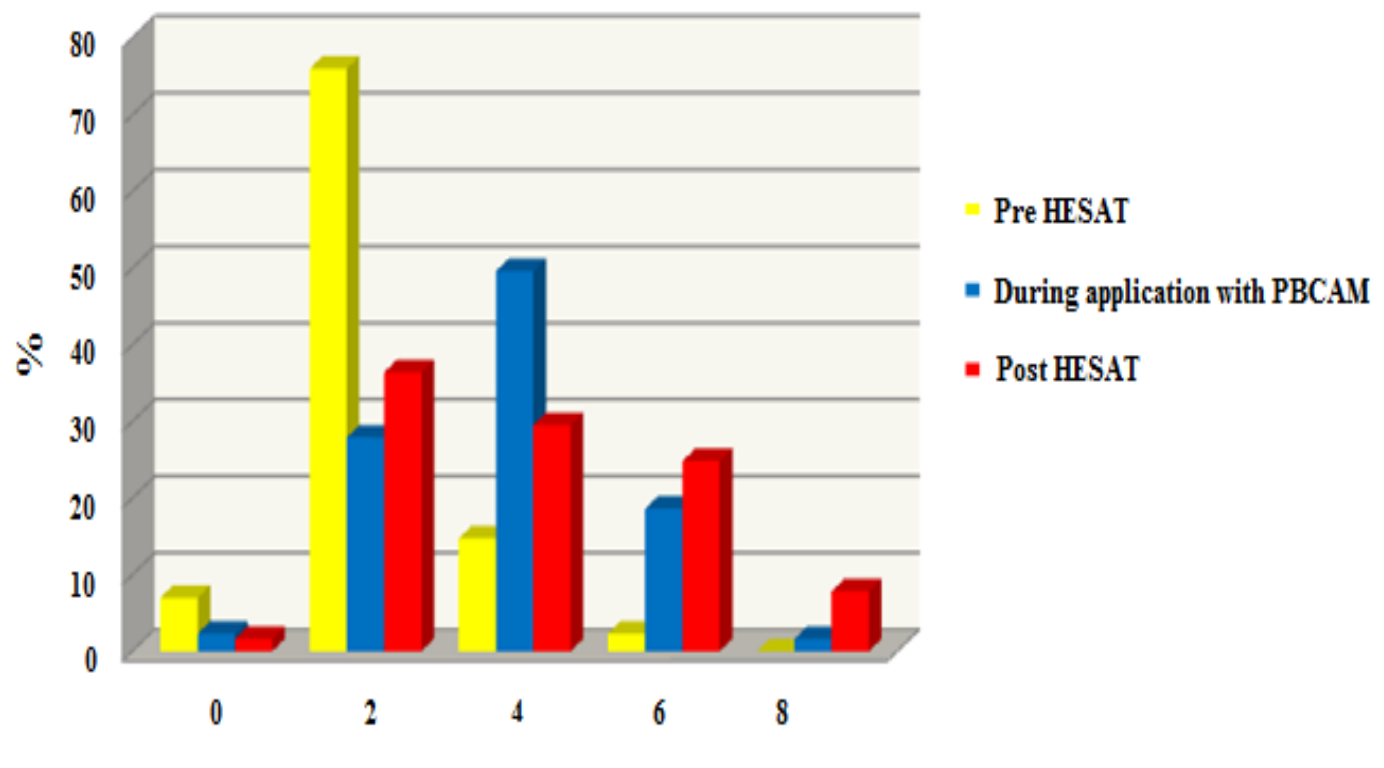

Figure 4. The students' usage level of the reasoning element 
When the process is taken into consideration as a whole, it is seen that the students generally sufficed with repeating their claims or they were insufficient in terms of explaining what kind of relation exists between the claim and the proofs they suggested. Similar results were obtained from the study conducted by Sandoval and Reiser [65] with the high school students studying the subject of evolutionary biology and the study conducted by Sandoval and Millwood [43] with the high school students studying the subject of natural selection. In these studies, the students failed to explain how the proofs they used in the scientific argumentation were related to the claims they made. Another study conducted by Jimenez, Rodriguez and Duschl [73] about genetics suggests that the insufficiency of proof and the insufficiency of reasoning were related to each other. In other words, the insufficiency of the proofs suggested by the students is directly related to their insufficiency in reasoning. The low level of the students' usage of the proof element in PBCAM during the problem solving process in this study also supports this assumption.

On the other hand, the fact that the students had a low level of using reasoning before the application can be explained with the insufficiency of their preliminary information. The students construct their information in the area about the problem while also solving the problem at the same time during the application process. The students are expected to structure the information they obtained from PBCAM by establishing a cause and effect relationship within the framework of the problem. The fact that the students could not explain how the proofs they suggested supported the claims they made can be associated with their inexperience in terms of using such kind of environments as also specified by Yerrick [67] and Aldağ [60]. As a natural result of this situation, the students may get bored when answering the questions in PBCAM, which render thinking visible, and tend to avoid the answers to these questions in detail. As a matter of fact, a previously specified statement by $\mathrm{S} 9$, with whom an interview was made, confirms this opinion.

It is possible to say that the students increased their level of using reasoning after the application. On the other hand, it is striking that the rate for using reasoning at level 8 was low during the study. It was seen that the students still tended to avoid explaining how the proofs they suggested supported their claims even after they had knowledge about the subject. According to Aldağ [60], reasoning requires being able to determine qualities regarding an object or situation, to classify this object or the situation and associate this object and situation with another object or situation. According to the researcher, if the person who learned the information does not have the relevant skill, such information, even if it is complete in nature, will be unprocessed and unassociated. Activities in PBCAM guide the students to associate the information they obtain during problem solving process by means of cause-based reasoning. However, considering the shortness of the application process, naturally the students, who encountered such an environment for the first time, are not expected to reason at a high level.

On the other hand, Jimenez, Rodriguez and Duschl [73], Kuhn and Reiser [58] suggest that the reason why the students avoid explaining how the proofs they specified supported their claims was because they could not completely comprehend the problem subjects in a conceptual sense. In this study, it was discussed that this reason suggested by the researchers in question might be one of the reasons why the students avoided explaining how the proofs supported their claims. As a matter of fact, a large part of the responsibility for learning was left to the students in PBCAM and the applications made in this environment. Therefore, the students also construct their information regarding the concepts in the problem on their own during the application process. It is natural that the understanding of the students with a superficial learning approach regarding the subject is also superficial. As a natural result of this situation, the students may avoid explaining the claims they made in a logical way.

\subsection{Findings Regarding the Conceptual Quality Level of the Claims Made by the Students}

In this study, the conceptual quality element defines whether or not a claim that was made was accurate, acceptable and valid from a conceptual point of view [1]. When the conceptual quality level of the claims made by the students in their scientific argumentation before, during and after the application are investigated, it is seen that approximately $97 \%$ of the conceptual quality of the claims the students made was at level 2 and 4 before the application while these levels were increased to $4(31 \%)$ and $6(48.1 \%)$ by the students. The students developed the conceptual qualities of the claims they made during the application process (see figure 5). On the other hand, while a slight increase was observed in the conceptual quality levels of the claims made at levels 4 and 6 in the final argumentation text prepared after the application, an important increase was observed at level 8 compared with to preliminary argumentation text $(0 \%)$ and the application process $(6.2 \%)$.

In addition to that, it is striking that the conceptual quality percentage of the claim that was made at level 2 at the end of the application $(2.9 \%)$ decreased slightly compared with to the time before the application (12.4\%) and the application process (14.8\%). All these values show that PBCAM and the applications made together with this environment improved the claims made by the students in conceptual terms.

When the process was investigated as a whole, it was determined that the students stated their claims in a clear and understandable manner within the framework of a question or problem even if it was partially valid. Similarly, the experimental study by Aldağ [60] shows that the claims made by the students before the application have higher averages compared to other scientific argumentation elements. No problems about students' use of the claim element are mentioned in the literature regarding scientific argumentation. 


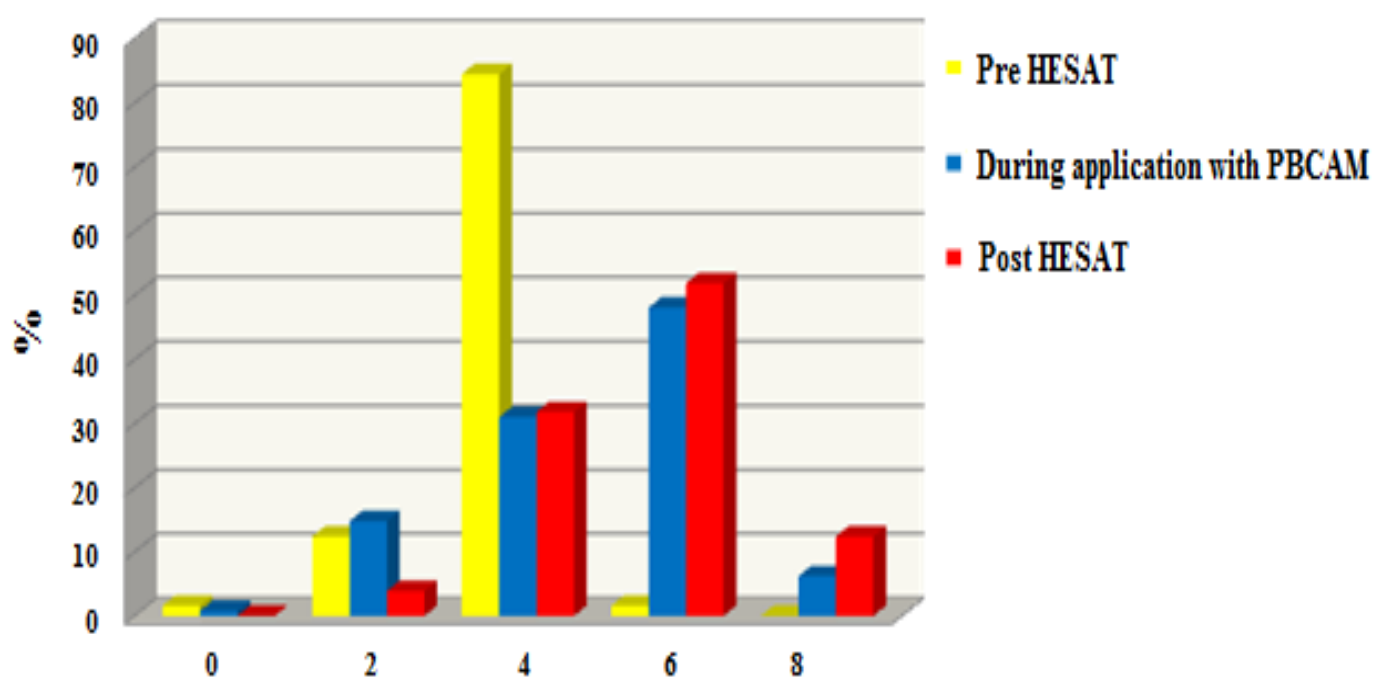

Figure 5. The conceptual quality levels of the claims made by the students

\section{Conclusion and Suggestions}

PBCAM and the applications made with this material improved students' skills for presenting claims in scientific argumentation. While students tended to present their claims with superficial information instead of inquiring about and researching the cause and effect relationship at the beginning of the application process, it was determined that they questioned and researched more towards the end of the application process, thus they were able to make more valid and stronger claims. PBCAM contributed to the development of students' skills for presenting claims in scientific argumentation because it allowed students to assume responsibility for their own learning during the problem solving process and to structure information by making discoveries on their own.

PBCAM and the applications made with this material improved students' skills for presenting proofs in scientific argumentation. It is striking that most of the proofs presented by the students before the application were inaccurate, implicit, irrelevant, unimportant, invalid and unreliable or the proofs that are based on a very small amount of the problem data. On the other hand, it is seen that the students started to present accurate, clear, valid and reliable proofs containing most of the problem data during the application process. Similarly, it is striking that the students presented a higher number of stronger proofs to support their claims also after the application.

PBCAM and the applications made with this material improved students' skills for reasoning in scientific argumentation. It was concluded that guiding questions like "Why do you think so?", "Are your thoughts and the result you reached after your observations the same?" and "Can you explain that a little bit more?" asked to students during the problem solving process directed students into inquiry and, with this aspect, PBCAM contributed to the development of the students' reasoning skills. Considering this result, guiding questions may be included to scientific argumentation based learning environments to be created in the future.

PBCAM and the applications made with this material improved the conceptual quality of the claims made by the students during scientific argumentation. Effective learning can be realized in biology teaching by developing learning environments with a similar approach for other subjects in the biology program.

Also, it was seen that "the Observation" section presented as a source of information in the study was effective on improving students' conceptual understanding. From this point of view, similar applications can be used also in teaching other biology subjects similar to endocrine system topic, which does not provide opportunities to conduct experiments and observations and which is hard to understand.

Information regarding how the students made research during the problem solving process, which sources of information they used more or less etc. was quite effective on the interpretation of the findings obtained from this study. If the time students spent in the sections of the research menu can be recorded with PBCAM, this will not only allow increasing the validity of the data obtained from the observations and the interviews but also make it possible to obtain more detailed information regarding problem solving performances of the students.

\section{REFERENCES}

[1] Sampson, V., \& D. Clark. 2008. Assessment of the ways students generate arguments in science education: Current perspectives and recommendations for future directions. Science Education 92 (3): 447-472. 
[2] Lazarowitz R. \& Penso, S., (1992). High School Students' Difficulties in Learning Biology Concepts, J.Biol. Educ., 26, $3,215-224$.

[3] Saka, A., (2001). Denetleyici ve düzenleyici sistemler ünitesi için öğretmen rehber materyallerinin geliştirilmesi, Yayınlanmamış Yüksek Lisans Tezi, Karadeniz Teknik Üniversitesi, Fen Bilimleri Enstitüsü, Trabzon.

[4] Tekkaya, C., Özkan, Ö. \& Sungur, S., (2001). Biology Concepts Perceived as Difficult By Turkish High School Students, Hacettepe Univ. J. Educ., 21, 145-150.

[5] Çimer, A., (2012). What Makes Biology Learning Difficult and Effective: Students' Views, Educational Research and Reviews, 7, 3, 61-71.

[6] Ministry of National Education, (2007). Secondary Education 10. Class Biology Curriculum, Ankara.

[7] Şahin, F. \& Parim, G., (2002). Problem Tabanlı Öğretim Yaklaşımı ile DNA, Gen ve Kromozom Kavramlarının Öğrenilmesi. V. Ulusal Fen Bilimleri ve Matematik Eğitimi Kongresi, Eylül, Ankara, 28,1-6

[8] Soderberg, P., (2003). An Examination of Problem-Based Teaching and Learning in Population Genetics and Evolution Using EVOLVE, A Computer Simulation, International Journal of Science Education, 25, 1, 35-55

[9] Alper, A. Y., (2003). The Effect of Cognitive Flexibility on Students' Achievement and Attitudes in Web Mediated Problem Based Learning, Unpublished Ph. D Dissertation, Ankara University, Educational Science Institute, Ankara.

[10] Sungur, S., (2004). An Implementation of Problem-Based Learning in High School Biology Courses, A Doctor of Philosophy Thesis, The Graduate School of Natural and Applied Sciences, Middle East Technical University, Ankara.

[11] Chin, C. \& Chia, L. G., (2004). Implementing Project Work in Biology through Problem-Based Learning, Journal of Biological Education, 38, 2, 69 -75.

[12] Akpınar, E. \& Ergin, Ö., (2005). Problem-Based Learning Approach Toward Student Opinions, Inönü University Education Faculty Journal, 6, 9, 3- 14.

[13] Tarhan, L. \& Acar, B., (2007). Problem-Based Learning in an Eleventh Grade Chemistry Class: Factors Affecting Cell Potential, Research in Science and Technological Education, $25,351-369$.

[14] Kumar, D. D. \& Sherwood, R. D., (2007). Effect of a Problem Based Simulation on The Conceptual Understanding of Undergraduate Science Education Students, Journal of Science Education and Technology, 16, 3, 239-246

[15] Tekedere, H., 2009. Web Tabanlı Probleme Dayalı Öğrenmede Denetim Odağının Öğrencilerin Başarısına Problem Çözme Becerisi Algısına ve Öğrenmeye Yönelik Tutumlarına Etkisi, Yayınlanmamıs Doktora Tezi, Gazi Üniversitesi, Eğitim Bilimleri Enstitüsü, Ankara

[16] Araz, G., (2007). The Effect of Problem-Based Learning on The Elementary School Students' Achievement In Genetics, Msc Thesis, Middle East Technical University, Graduate School of Social Sciences, Ankara.

[17] Kelly, O. \& Finlayson, O. E., (2007). Providing Solutions Through Problem-Based Learning For The Undergraduate $1^{\text {st }}$
Year Chemistry Laboratory, Chemistry Education Research and Practice, 8, 3, 347-361.

[18] Krowczyk, T. D., (2007). Using Problem Based Learning and Hands On Activities To Teach Meiosis and Heredity in a High School Biology Classroom, MS Thesis, Michigan State University, Michigan, USA.

[19] Tatar, E., (2007). The Effect of Problem Based Learning Approach on Understanding of First Law Of Thermodynamics, Unpublished Ph. D Dissertation, Atatürk University, Science Institute, Erzurum.

[20] Skolnick, R., (2009). Case Study Teaching a High School Biology: Effects of academic achievement problem solving skills, team work skills and science attitudes, Phd Thesis, Touro University International, California, USA.

[21] Kelly, O. \& Finlayson, O., (2009). A Hurdle Too High? Students' Experience of a PBL Laboratory Module, Chemistry Education Research and Practice, 10, 42-52.

[22] Serin, G., (2009). The Effect of Problem Based Learning Instruction on $7^{\text {th }}$ Grade Students' Science Achievement, Attitude toward Science and Scientific Process Skills, Phd Thesis, Middle East Technical University, Secondary Science and Mathematics Education Department, Ankara.

[23] Wong, K. K. H. \& Day, J. R., (2009). A Comparative Study of Problem-Based and Lecture Based Learning in Junior Secondary School Science, Research in Science Education, $39,625-642$.

[24] Rissi, R. J., (2010). Efficacy of Problem Based Learning in a High School Classroom, Master Thesis, Michigan State University, USA.

[25] Tatar, E., \& Oktay, M., (2011). The Effectiveness of Problem-Based Learning on Teaching The First Law Of Thermodynamics, Research in Science \& Technological Education 2 29, 3, 315-332

[26] Tosun, T. \& Taşkesengil, Y., (2011). Using the MOODLE Learning Management System in Problem Based Learning Method, International Online Journal of Educational Sciences, 3, 3, 1021-1045

[27] Kaptan F. \& Korkmaz H., (2001). Problem Based Learning Approach in Science Education, Hacettepe University Education Faculty Journal, 20,191-192

[28] Hung, W., Bailey, J.H. \& Jonassen, D.H., (2003). Exploring the Tensions of Problem-Based Learning: Insights From Research, New Directions for Teaching and Learning, 95, $13-23$

[29] Hoffman, B. and Spatariu, A., (2008). The Influence of Self-Efficacy and Metacognitive Prompting on Math Problem-Solving Efficiency, Contemporary Educational Psychology, 33, 4, 875-893.

[30] Kauffman, D. F., Ge, X., Xie, K., \& Chen, H., (2008). Prompting in Web-Based Environments: Supporting Self-Monitoring and Problem Solving Skills in College Students, Journal of Educational Computing Research, 38, 115-137.

[31] Angeli, C., (2002). Teachers' Practical Theories for the Design and Implementation of Problem-Based Learning, Sci. Educ. Int., 13, 3, 9-15. 
[32] Uden, L. \& Beaumont, C., (2006). Techonology and Problem-Based Learning. London, UK., Information Science Publishing, $344 \mathrm{p}$.

[33] Jonassen, D. H., (2010). Learning to Solve Problems: A Handbook, Routledge, Newyork, 340s.

[34] Corliss, B. S., (2005). The Effects of Reflective Prompts and Collaborative Learning in Hypermedia Problem-based Learning Environments on Problem Solving and Metacognitive Skills, Phd Thesis, University of Texas, Austin, USA.

[35] Şendağ, S., (2008). The Effect Of Online Problem Based Learning On The Pre-Service Teachers' Critical Thinking Skills and Academic Achievement, Unpublished Ph. D Dissertation, Anadolu University, Educational Science Institute, Eskişehir.

[36] Chang, C. Y., (2001a). A Problem- Solving Based ComputerAssisted Tutorial for the Earth Science, Journal of Computer Assisted Learning, 17, 263-274.

[37] Chang, C. Y., (2001b). Comparing the Impacts of a Problem-Based Computer-Assisted Instruction and the Direct-Interactive Teaching Method on Student Science Achievement, Journal of Science Education and Technology, $10,2,147-153$.

[38] Lee, C. B., (2006). Capturing and Assessing Conceptual Change in Problem Solving, Phd Thesis, University of Missouri, Columbia, USA.

[39] Wesolowski, M. C., (2008). Facilitating Problem Based Learning in an Online Biology Laboratory Course, Unpublished Phd Thesis, University of Delaware, USA.

[40] Krange, I. \& Ludvigsen, S., (2008). What Does It Mean? Students' Procedural and Conceptual Problem Solving in a CSCL Environment Designed within the Field of Science Education, Computer-Supported Collaborative Learning, 3, 25-51.

[41] Yu, W. F., She, H. C., \& Lee, Y. M., (2010). The Effects of a Web-Based/Non Web-Based Problem Solving Instruction and High/Low Achievement on Students' Problem Solving Ability and Biology Achievement, Innovations in Education and Teaching International, 47, 2, 187-199.

[42] Leitao, S., (2000). The Potential of Argument in Knowledge Building, Human Development, 43, 6, 332-360.

[43] Sandoval, W. A. \& Millwood, K. A., (2005). The Quality of Students' Use of Evidence in Written Scientific Explanations, Cognition and Instruction, 23, 1, 23-55.

[44] Köroğlu, L.S., (2009). The Effect of Argumentation Scaffolds In Simulation On Academic Success and Argumentation Structure Use In The 8th Grade Genetic Unit, Unpublished Master Dissertation, Çukurova University, Social Sciences Institute, Adana.

[45] Belland, B. R., Glazewski, K. D. \& Richardson, J. C., (2011). Problem-Based Learning and Argumentation: Testing a Scaffolding Framework to Support Middle School Students' Creation of Evidence-Based Arguments, Instructional Science, 39, 667-694.

[46] Sampson, V. \& Gleim, L., (2009). Argument-Driven Inquiry to Promote the Understanding of Important Concepts \& Practices in Biology, The American Biology Teacher, 71, 8, 465-472.
[47] Creswell, J. W., (2009). Research Design: Qualitative, Quantitative, and Mixed Methods Approaches, 3rd ed., Los Angles: Sage.

[48] Güneş, C., (2006). Endokrin Sistemleri Ünitesinde Problem Çözmeye Dayalı Öğretimin Akademik Başarıya ve Tutuma Etkisinin Araştırılması, Unpublished Master Dissertation, Gazi University, Science Institute, Ankara.

[49] Little, S., (1997). Preparing Tertiary Teachers for Problem-Based Learning the Challenge of Problem-Based Learning, 2nd Edition, Eds: Boud, D. and Feletti, G. I., London, 117-124

[50] Patton, M. Q., (1987). How to Use Qualitative Methods in Evaluation, CA: Sage, Newbury Park.

[51] Hung, W., (2006). The 3C3R Model: A Conceptual Framework for Designing Problems in $\mathrm{Pbl}$, The Interdisciplinary Journal of Problem-based Learning, 1, 1, 55-77.

[52] Vekli Sezen, G., \& Çimer, A. (2012b). Evaluating Computer Assisted Problem Based Learning Environment for Endocrine System in Human Beings in View of Professionals, Procedia Social and Behavioral Sciences, 47, 218-224

[53] Hung, W., (2009). The 9-Step Problem Design Process for Problem-Based Learning: Application of the 3C3R Model, Educational Research Review, 4, 118-141.

[54] Vekli Sezen, G., \& Çimer, A. (2012a). Designing Computer Assisted Problem Based Learning Environment in the Subject of Endocrine System in Human Beings for High School Biology, Procedia Social and Behavioral Sciences, 47, 303-310

[55] LeCompte, M.D. \& Goetz, J.P., (1982). Ethnographic Data Collection And Analysis in Evaluation Research, Educational Evaluation and Policy Analysis, Fall, 387-400.

[56] Miles, M. B. \& Huberman, A. M., (1994). Qualitative Data Analysis, 2nd Ed., Thousand Oaks, CA: Sage.

[57] Luft, J. A., (1997). Design Your Own Rubric, Science Scope, 20, 5, 25-27.

[58] Kuhn, L. \& Reiser, B., (2005). Students Constructing and Defending Evidence-Based Scientific Explanations, National Association for Research in Science Teaching, Dallas, Texas.

[59] Choi, A., Hand, B. \& Norton, M.. (2010). Examining Argument Structures Developed by Students Engaging in Online Discussion on Inquiry Investigations, Annual International Conference of National Association for Research in Science Teaching, Philadelphia, PA.

[60] Aldağ, H., (2005). The Effects Of Textual and Graphical-Textual Argumentation Software As Cognitive Tools On Development Of Argumentation Skills, Unpublished Ph. D Dissertation, Çukurova University, Social Sciences Institute, Adana.

[61] Bell, P. \& Linn, M. C., (2000). Scientific Arguments as Learning Artifacts: Designing For Learning from the Web with KIE, International Journal Of Science Education, 22, 8, 797-817.

[62] Ekinci, N., (2009). Learning Approaches of University Students, Education and Science, 34, 151, 74-88. 
[63] Ramsden, P. (2000). Learnig To Teaching In Higher Education, London: Newyork Routhladge Falmer

[64] Cuthbert, P. (2005). The Student Learning Process: Learning Styles or Learning Approaches, Teaching in Higher Education, 10, 2, 235-249.

[65] Sandoval, W.A. \& Reiser, B.J., (1997). Evolving Explanations in High School Biology, Annual Meeting of the American Educational Research Association, Chicago.

[66] Keys, C. W., (1999). Revitalizing Instruction in Scientific Genres: Connecting Knowledge Production with Writing to Learn in Science, Science Education, 83, 115-130.

[67] Yerrick, R. K., (2000). Lower Tarch Science Students' Argumentation and Open Inquiry Instruction, Journal of Research in Science Teaching, 37, 807-838.

[68] Dawson, V. \& Venville, G. J., (2009). High-School Students' Informal Reasoning and Argumentation about Biotechnology: An Indicator of Scientific Literacy?, International Journal of Science Education, 31, 11, 1421-1445.
[69] Zembal-Saul, C., Munford, B., Crawford, P., Friedrichsen, D. \& Land, S., (2001). The Examining the Role of Software Scaffolds in the Development of Prospective Science Teachers, Explanations in Biology, Meeting of The National Association For Research in Science Teaching, St. Louis, Mo.

[70] Fischer, F., Troendle, P. \& Mandl, H., (2003). Using the Internet to Improve University Education: Problem-Oriented Web-Based Learning with MUNICS, Interactive Learning Environments, 11, 3, 193-214.

[71] Yıldırım, H. İ., (2001). A Research on Determination of 6., 7. ve 8. Primary Students Misconception about Electricity, Unpublished Master Dissertation, Gazi University, Educational Science Institute, Ankara

[72] Chinn, C. A. \& Brewer, W. F., (1998). An Empirical Test of a Taxonomy of Responses to Anomalous Data in Science, Journal of Research in Science Teaching, 35, 623-654.

[73] Jimenez-Aleixandre, M P., Rodriguez, A. B., \& Duschl R., A., (2000). Doing the lesson or doing science: Argument in high school genetics., Science Education, 84, 6, 757-792 